\title{
Extending flood damage assessment methodology to include sociological and environmental dimensions
}

\author{
MF Viljoen*, LA du Plessis, HJ Booysen \\ Department of Agricultural Economics, University of the Free State, Bloemfontein, South Africa
}

\begin{abstract}
Optimal and sustainable flood plain management, including flood control, can only be achieved when the impacts of flood control measures are considered for both the man-made and natural environments, and the sociological aspects are fully considered. Until now, methods/models developed to determine the influences of floods and flood control measures in South Africa, and elsewhere in the world, focus on the man-made environment and neglect the natural environment and social dimensions. Two models, recently completed in South Africa, namely FLODSIM (flood damage simulation model for irrigation areas) and TEWA (flood damage simulation model for urban areas) are cases in point.

This paper gives an overview of the development of flood damage assessment and mitigation methodology in South Africa. Emphasis is placed on the evolution from the traditional ex-post approach to the latest ex-ante approach in which the sociological and natural environmental dimensions are included. Deliverables from the presentation should be of value to researchers and managers in the fields of flood management and environmental impact assessment worldwide.
\end{abstract}

\section{Introduction}

Scientific research on flood damage in South Africa has had a fairly short history. Discussion of the developmental or growth path of the research is required to map out new directions. The initial research (the ex-post phase) with its narrow focus was necessary to set the stage for the subsequent ex-ante phase. Developments during the ex-ante phase range all the way from locality-specific models through generalised models to a holistic approach. The latter provides for the social and environmental impacts which are discussed later in the paper.

\section{Ex-post research phase}

Serious, concerted scientific research into flood damage determination in South Africa started in 1975 (after extensive flooding in 1974) when the Institute for Social and Economic Research of the University of the Free State and the Bureau for Economic Research of the University of Stellenbosch were commissioned by the Water Research Commission (WRC) to scientifically determine the nature and extent of the damage caused by the 1974 floods. The specific aims for this ex-post research phase were as follows (Viljoen, et al., 1977):

- To develop a methodology to identify and evaluate all forms of flood damage.

- To apply the methodology in specified river reaches so as to determine the damage for each reach.

- To describe the circumstances of each damage in such a way that a logical relationship between physical damage and flood circumstance could be established, thereby utilising the 1974 flood to construct a paradigm.

- To formulate the paradigm in such a way that the results would provide guidelines for application in other rivers.

\footnotetext{
* To whom all correspondence should be addressed.

푱(051)401-2213; fax:(051)401-3473; e-mail:viljoemf@sci.uovs.ac.za

Received 3 October 2000; accepted in revised form 12 July 2001.
}

The research involved with this project was conducted over the period 1975 to 1982 . Of this research phase, the following characteristics, which are important for this paper, should be noted.

- The fundamental premise for determining damage was anthropocentric (flood effects were regarded as damage when the community suffered losses).

- The main emphasis was on determining direct tangible damage while the intangible damage was only described partially.

- The relationships between physical damage and flood circumstances were depicted by loss functions. The motivation for developing loss functions was that they are necessary building blocks in the traditional approach to determine an optimal set of flood control/mitigation measures for a flood area.

The data obtained during the ex-post phase were not sufficient to construct a complete set of loss functions needed for flood control planning. It was, in fact, possible to determine loss functions only for a few land-use types. It was a recommendation to supplement and/or follow the ex-post phase by ex-ante research. Ex-ante research would render it possible to construct loss functions without floods actually occurring. This would also allow for a complete set of loss functions to be developed.

\section{Ex-ante research phase}

After extensive flooding in 1988 and a request to revise the national flood disaster policy for South Africa, the WRC provided funds to the Department of Agricultural Economics at the University of the Free State to start the ex-ante research phase. This phase which can be subdivided into three sub-phases, started with the same basic premises of the ex-post phase as its point of departure (anthropocentric, focus on direct damage, loss functions needed for optimal flood control planning in cost-benefit framework).

The aims of the first phase (1991 to 1994) were specified as follows (Viljoen et al., 1996): 


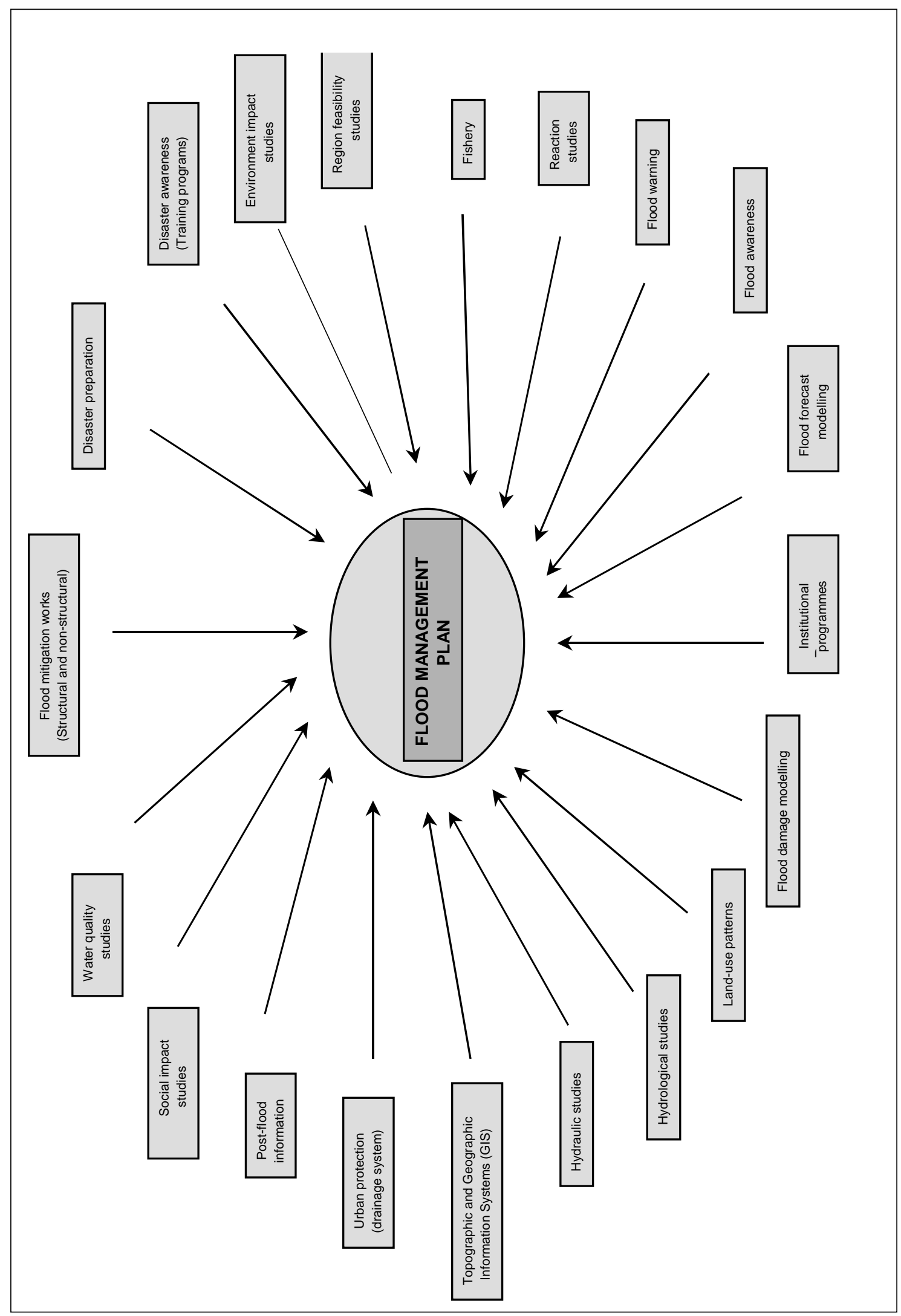

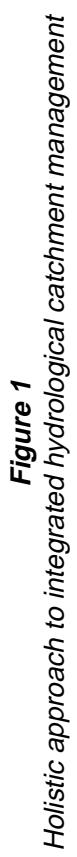


- To develop loss functions to determine potential damage for different land use types in demarcated flood plains of the specified research area.

- To develop the outline of a computer database in which loss function can be stored and apply it to the research area.

- To develop a computer program to determine the benefits of different combinations of flood control measures with the loss functions in the database.

- To demonstrate the application of the computer program for flood management planning in the research area.

In this phase, it was possible to develop a complete set of loss functions for the research area (Upington on the Orange River and Vereeniging on the Vaal River), and to develop computer programs to determine optimum combinations of flood control measures. A computer simulation program, called FLODSIM was developed for the irrigation area and another, called ANUFLOOD (developed by CRES in Australia) was adapted for the urban areas.

Phase 2 (1995 to 1997) was necessary in order to overcome the shortcomings of the results of Phase 1, i.e. the location specificity of computer programs and loss functions. The research area was expanded to include the Mfolozi sugar cane production area in Kwazulu-Natal, the Uitenhage and Despatch formal urban areas along the Swartkop River in the Eastern Cape and the Soweto on Sea informal urban area along the Chatty river, also in the Eastern Cape. The specific aims were as follows (Du Plessis et al., 1999):

- Development of flood damage functions for alternative land use types in floodplains in irrigation and urban areas of South Africa.

- Further development of flood damage models and computer programs to be more generally applicable in irrigation and urban areas. Besides the utilisation of new technology like remote sensing, the models should also be adapted to be applicable at three levels of decision-making, namely local, provincial and national level and should also be in accordance with the revised national flood management policy. Development of guidelines to make the policy executable at three government levels should also receive attention.

- To test, validate and verify the models and computer programs in selected areas.

Generalised computer programs (FLODSIM and TEWA; the latter a GIS program utilising the same information as ANUFLOOD) and standardised loss functions resulted from this research. It has now become possible to apply them as flood control planning and management tools in different flood plains in South Africa. In order to obtain full benefits, it is recommended to apply these aids as part of a holistic approach to integrated hydrological catchment management, as is shown schematically in Fig. 1.

Phase 3 was conducted with this in mind. This phase is aimed mainly at the refinement of the computer programs, loss functions and questionnaires, and dissemination thereof as flood management aids to all interested parties and role-players involved in flood plain and flood control planning in South Africa. As the programs are still new, the usefulness and acceptability of the products in actual flood control planning in urban and irrigation areas have yet to be demonstrated further. Experience may dictate refinements and alterations in future.

\section{Social impact/acceptability}

Besides applying and testing FLODSIM and TEWA in actual case studies along the Orange and Swartkops rivers, a sociological study was done to determine the suitability of the approach to determine acceptable flood control mitigation measures for a developing local community. The Community Agency for Social Enquiry (CASE) was commissioned to research the flood affected community of Pietermaritzburg, which experienced the 1995 Chrismas Day flood. Aims and findings of the CASE research were to be specifically oriented to ensure that the process would contribute toward, and assess the feasibility of, the following (Butler, 1998):

- Determination of the social acceptability of different flood damage control measures for different communities/target groups in order to design acceptable combinations of measures, and development of education/extension programs to promote acceptability, change perceptions (if necessary) and build awareness of the flood problem.

- Development of a questionnaire (or questions for inclusion in the economic questionnaire) to measure the sociological and social consequences/impacts of flooding.

- Development of procedures or guidelines for technology transfer of the aid measures developed for flood damage assessment and flood damage control planning in irrigation and urban areas.

- Development of guidelines/sociological criteria to ensure optimum and sustainable institutional arrangements, responsibilities and synchronisation of effort in respect of flood and disaster management and response.

- Development of guidelines to improve flood communication with regard to formulating flood warning messages and identifying the most effective communication channels with the community.

- Development of a methodology to promote local community involvement in policy formulation and allocation of responsibilities with regard to flood management planning.

This research clearly indicated that a number of changes were needed in the adopted approach. The following changes are needed with reference to the premises of the approach (Butler, 1999).

- Focus on the direct tangible damage (which uses the monetary value of damage as a yardstick) must be changed. Instead of simply assessing the value and extent of losses in monetary terms, a relative impact index should be calculated by weighing monetary losses by either household incomes or the value of household possessions. This index will be more reflective of actual damage and should also capture some of the intangible damage. Butler (1999) justifies this requirement as follows:

"Damage assessment has relied too often on quantification in terms of monetary valuations of damage. This approach produces gross distortions - damage sustained in affluent or highly developed areas calculated in this manner is inevitably both higher (because of the monetary value of housing, infrastructure, possessions and general levels and intensity of investment) and more measurable (especially because large components are quantified for insurance claims). Neither of these (higher or more readily measurable values) give any indication of the extent to which a disaster has been disastrous. The quantifiable monetary value of damage in a poor informal settlement, for example, will be less, but its impact is more likely to be catastrophic at a number of levels (including 
economic) from a human development perspective. For example, one could:

- investigate and assess not just loss of property, but impacts on income.

- $\quad$ assess to what extent livelihoods were dependent on what was destroyed or damaged by the disaster - many 'informal sector' and other economic activities engaged by the poor are dependent on servicing various needs within the immediate community."

- The cost benefit technique, which typically uses one criterion (economic efficiency), does not effectively incorporate other concerns. These include distribution issues, social and environmental impacts, and a wider range of stakeholders. Multiple criteria decision analysis (MCDA), with wide participation of all concerned, is suggested. In the MCDA approach the focus is on finding satisfactory alternatives that are acceptable across a number of objectives as opposed to optimal solutions that deal with single objective functions. It is stated by Butler (1999) that it should be recognised that local people have knowledge, information and wisdom that are legitimate and significant. Thus, participation should not be limited to a process of more thoroughly 'telling people what they need to know' or what the 'real' situation is and where the assumption remains intact that the experts have full and complete data as well as the appropriate sets of options and solutions. In the Pietermaritzburg flood case study, officials were more or less compelled to acknowledge that, to an important degree, it was their incomplete knowledge and experience that had to change in order for them to respond effectively. Further on in the report, it is said "ultimately, in relation to the question of social acceptability of different flood damage control measures, while one would certainly suggest that the basic elements of sound participative and consultative mechanisms should be employed, it is perhaps not the issue of 'acceptability' that is paramount but rather 'appropriateness', where acceptability is one factor amongst others that guide the search for interventions that are effective, developmental, sustainable and 'in the public interest.' "'

- The anthropocentric basis of identifying and quantifying the effects of floods must broaden so that the sociological dimension also receives proper attention. In this regard Butler (1999) states:

"With regard to the question of measuring the sociological and social consequences/impacts of flooding, it seems unlikely that disaster management can aim to 'repair' sociological damage to a large extent since the social fabric is woven from so many diverse strands - and is constantly being woven. A consideration of the Pietermaritzburg flood case study suggests, however, that the practice of disaster response could demonstrate sensitivity to the social impacts of disasters by, for example:

avoiding the prolonging of the 'transitional welfare' phase which runs the real danger of destroying initiative and a sense of self-worth

- seek out ways for those who are capable and willing to actively engage in, and exercise control over relief, remediation and development activities - but without assuming that these capacities are there in equal measure throughout the communities affected by a disaster

whatever the social impacts of the disaster event itself (and the case study has demonstrated how multi-faceted and catastrophic these can be), avoid responses to the disaster which themselves are likely to compound or add new negative social consequences - e.g. replacing family homes with one-bedroomed houses

- integrate trauma counselling for individuals and groups into the overall disaster response process."

- The anthropocentric basis for identifying damages and damage mitigation measures must be supplemented with an environmental basis. This will add substantially to determining socially acceptable and environmentally friendly flood management options within a wider (more holistic) disaster management and developmental approach.

\section{Environmental impact}

Ways in which the environmental impact of flood and flood mitigation measures should be accounted for in the analysis must be developed further. Dougherty and Hall (1995) say, for instance, that "it had not been found easy to incorporate environmental impacts into cost benefit analysis". A variety of techniques are of value to supply information for the environmental impact assessment of the effects of floods and flood mitigation measures. Techniques include baseline studies, the ICID checklist, matrices, network diagrams, overlays, mathematical modeling, expert advice and environmental economic techniques (Dougherty and Hall, 1995). It is foreseen that one or more of these techniques (depending on the environmental issue to be addressed) will provide useful information to construct an environmental impact statement on the relevant issue. This statement can then be incorporated into a MCDA framework for due consideration and better informed decisionmaking.

Further research is necessary on both the social and environmental impacts of flooding and how to integrate them with economic impacts in a useful decision-making framework.

\section{Conclusions}

The different phases of flood damage assessment research in South Africa represent a learning curve experience. Experience and insight were gained and these were implemented to improve the methodological development process. The flood damage management aids (FLODSIM and TEWA) which were finalised during Subphase 3 of the ex-ante research, have already proved to be useful in certain practical applications. The usefulness should, however, be improved further when applied within a more holistic framework that accounts fully for the relevant sociological and environmental aspects.

Results of the sociological study conducted at Pietermaritzburg, suggested, for instance, that the monetary value basis of damage assessment used in FLODSIM and TEWA is inadequate to fully capture the social impact. A relative impact index, that takes household income and value of household goods into account, promises to be much more reflective of actual damage sustained by households. The single economic efficiency criteria basis of the cost-benefit analytical framework used in FLODSIM and TEWA to determine flood control measures is also too narrow. A MCDA approach including other criteria besides economic efficiency should be applied. This approach will, for instance, capture fully the knowledge, information, wisdom and needs of local people during the preparation and repair phases of a flood.

Including the environmental impact dimension into the holistic flood damage assessment methodology should render further benefits. Although this needs to be researched, it is envisaged that the incorporation of environmental impact statements into a MCDA 
framework would lead to better informed decision-making. This should apply internationally and not just to South Africa.

\section{Acknowledgement}

Financial support from the WRC is hereby acknowledged.

\section{References}

BUTLER M (1998) Community Agency for Social Enquiry Progress Report on Flood Research. Pietermaritzburg.

BUTLER M (1999) Community Agency for Social Enquiry Progress Report on Flood Research. Pietermaritzburg.

DOUGHERTY TC and HALL AW (1995) Environmental impact assessment of irrigation and drainage projects. FAO Irrigation and Drainage Paper 53.
DU PLESSIS LA, VILJOEN MF, WEEPENER HL and BERNING C (1999) Flood Damage Functions, Models and a Computer Program for Irrigation Areas in South Africa. 1: Irrigation Areas. The Univ. of the Free State, Dept. of Agric. Econ., Bloemfontein. WRC Report No 690/ $1 / 99$.

VILJOEN MF, DU PLESSIS LA and BOOYSEN HJ (1996) The Development of Flood Damage Functions and a Computer Program to Determine the Benefits of Flood Control and Flood Damage Control Measures. Part 1: Summary Report. Report to the Water Research Commission by the Univ. of the Free State, Dept. Agric. Econ., Bloemfontein. WRC Report No 490/1/96.

VILJOEN MF, SMITH DJG and SPIES PH (1977) Flood Damage in Certain River Reaches of the RSA - Part I, A Methodology for Flood Damage Determination. Univ. of the Free State, Inst. for Soc. and Econ. Res., and Univ. of Stellenbosch, Bureau for Econ. Res. September. 
